Article

\title{
Interactive Game-Content-Based Storytelling for the Environment
}

\author{
Youngsoo Lee and Joosung Lee * \\ Division of Interdisciplinary Studies, Soonchunhyang University, Asan 31538, Korea; lysoo@sch.ac.kr \\ * Correspondence: jsl@sch.ac.kr; Tel.: +82-41-530-4974
}

Received: 11 August 2020; Accepted: 30 September 2020; Published: 6 October 2020

\begin{abstract}
To plan a persuasive environmental campaign, it is important to tell consumers environmental messages in an engaging manner, to encourage user participation. To explore the effective approaches to storytelling for environmental innovation, this study analyzes how varying interaction modes based on the interactivity levels of user participation framework influence people's response to an environmental mission such as planting trees. This research has developed and employed various forms of interactive contents, such as problem-solving, mission-driven games to increase consumer awareness and induce pro-environmental actions. This research first reviews previous studies on game approaches and storytelling for environmental issues. It then explores how the different levels of interactive storytelling with the game content types induce consumer responses to a green product purchase or environmental protection campaign donation. Practical implications of environmental storytelling approaches and the use of interactive game content are also discussed.
\end{abstract}

Keywords: storytelling; interactivity; pro-environmental games

\section{Introduction}

Today, consumers are increasingly aware of environmental issues and possess high levels of environmental concern [1]. Many opt for pro-environmental behavior; for example, according to a recent study, more concerned consumers would pay more for environmentally friendly products and services [2]. Such consumers with high environmental awareness tend to purchase green products more often [3]. On the other hand, people with less knowledge about environmental issues are more interested in just product prices, functions, and packaging rather than environmental features [4].

The environmental awareness (i.e., knowing the importance of protecting the environment and literacy in related terminology) does not result in specific actions for sustainable innovation [5]. For example, plastic pollution and non-combustible waste have been increasing continually. Some plastic wastes from the eastern coast of Asia even float around and travel all the way to the Pacific islands. The amount of waste dumped without being recycled has reached a level that poses a serious threat to the global ecological system [6].

Today, it is necessary to encourage consumers to take more specific actions in order to prevent natural resource depletion and to mitigate environmental damage caused by waste materials that are not properly recycled. To strengthen the environmental orientation of the consumers' mindset, researchers and marketers should seek more effective ways to craft and deliver sustainability messages to encourage pro-environmental actions. Storytelling could be one powerful form of communicating such messages, helping shape people's attitude toward the consumption of green products $[7,8]$. Through storytelling, artists have often used various forms of work to influence the audience on socio-environmental themes such as global climate change, ecological conservation, and social responsibility [7,8]. In doing so, they have used a persuasive story containing a pro-environmental message. 
Some studies have proposed that artists use visual elements and narratives to impact the attitudes of consumers toward pro-environmental consumption [9-12] because storytelling used by artists could even lower emotional barriers to implementing pro-environmental measures [13]. However, specific environmental storytelling techniques and their effects on natural conservation have been lacking. Therefore, the storytelling approaches introduced in this research can help those developers of art or game content to make their work more engaging and interactive, so that the users become action-takers and not just observers regarding environmental conservation.

Previous studies have examined how games can be used for social innovation purposes. McGonigal [14] pointed out the cognitive, emotional, and social benefits for the players if they get involved in the development and playing of games for social causes such as climate change prevention and poverty eradication. Examples of such games include EVOKE, which operated a 10-week long game where the players got a new mission each week to deal with hunger, poverty, and water shortage problems around the globe and thus gained an increased awareness of these social issues. It was played globally five times since 2010. Additional games successfully developed and played for the environment include Save the Ocean and mobile-device-based games that raise awareness of environmental issues [15]. Tackling environmental issues with an educational game, Enviropoly, Arslana et al. [16] developed a board game to be used by young students. Initial trials showed that it could contribute to environmental literacy and interest in getting involved in environmental conservation activities.

While there are several case studies [14-16] in which interactive game contents have been used to educate the public and induce environmental innovation via consumers' adoption of more environmentally friendly products and services, empirical studies in this area have been scarce. In particular, the interactivity effects of the contents on the viewer's attitude toward environmental conservation are worth examining. That is, the contents presented by games (and art) usually exhibit different levels of interactivity with the player (and viewer), and when it comes to sustainability and environmental messaging, one should examine whether more interactively designed contents can deliver a more persuasive environmental message for the user's specific intention to engage in pro-environmental consumption or to participate in such campaigns.

Storytelling is a technique that has been developed to bring a human experience to life. When used in art/game contents, it could affect the attitude and even behaviors of the players. McGonigal [17] employed gamified study contents and found that students became more motivated and less fearful of trying out unfamiliar, more advanced problems, which could lead to higher academic performance. George et al. [18] encouraged forming a group narrative by distributing stage-after-stage drawings among dementia patients and their student caregivers. This promoted patient-caregiver interaction and also helped develop positive viewpoints.

Against this backdrop, this research analyzes various types and levels of interactivity of the game contents and their environmental messages' effects on the consumers' attitude from the perspective of storytelling. Storytelling is an appropriate frame of analysis to classify the types and levels of interactivity in the game contents in this research because all such contents have a specific purpose, convey their message, and leave the player with a set of experiences that impact one's mindset and even further actions. In this paper, we will use this methodology to analyze the interactive storytelling of the game contents with environmental themes and to research how consumers perceive participating in pro-environmental campaigns. We will study how consumers respond to environmental campaign messages according to the interaction levels of the game contents. This will allow us to examine effective participatory storytelling designs to achieve desirable outcomes (i.e., pro-environmental behavior). Depending on how interactively and engagingly the game contents can convey the message, the participation intentions of the player (e.g., whether or not the consumer feels like donating money for tree planting) will differ. Therefore, this research seeks to understand how interactive contents that contain environmental themes affect the consumers' intention to purchase a green product/service or to participate in an environmental campaign. Overall, this research will look into the usefulness 
of interactive, environmental storytelling designs in game contents in order to achieve the desired environmental actions.

\section{Literature Review on Pro-Environmental Storytelling}

\section{Pro-Environmental Storytelling}

The theory of storytelling has been developed to analyze and to construct immaterial human experiences. While a traditional story presupposes an author with a message and an audience to receive it, the present storytelling is a compound word of story + tell $+i n g$, and presupposes an ongoing, collaborative, and interactive conversation between the author and the audience [19]. Through storytelling, the audience becomes an active participant, producing new meaning on top of the structure created by the author.

In pro-environmental storytelling, our audience should participate in the message through interactive storytelling, rather than unilaterally receiving messages for the environment. Therefore, pro-environmental storytelling is a methodology for producing environmental messages, but it is also a means to analyze the experience of participating in relevant campaigns by receiving messages about the environment.

Some storytelling-based approaches to environmental issues have revealed this can be an effective means to achieve natural sustainability. Effective storytelling for raising environmental awareness in young students was described as education research [7]. Over the past decade, using storytelling in energy and climate change research has become available in various forms [9].

Based on the literature review of uses of storytelling and game content for environmental issues, we conducted a case study research that uniquely incorporates experiments to confirm our research propositions. In a case study research, "propositions or frameworks provide direction, reflect the theoretical perspective, and guide the search for relevant evidence" [20]. Therefore, we have posed the propositions of our study as follows:

1. Use of an appropriate mode of storytelling can raise people's awareness on environmental issues and motivate actions that are helpful for the environment.

2. Advanced modes of storytelling using game content can provoke more than an emotional response toward the environment and help develop attitudes resulting in concrete actions for environmental protection.

As one of the storytelling methodologies, there is a user participation framework that examines the aspect of interactive storytelling and the level of user participation according to the level of interaction. The following section presents a storytelling approach, which is the framework of analysis in this paper.

\section{Research Methods}

\subsection{Storytelling Approach as a Framework of Analysis}

Interactivity is without doubt a central concept with regard to audience participation; however, the degree of engagement level is different between interactivity and reaction. For example, would we feel much interactivity in the case of a door that automatically opens and closes door in front and behind us, operated by a sensor? If the action of pressing a floor button and the reaction of exiting the elevator upon arrival on our destination are to establish interactivity, is it possible to make such elevator-riding experience enjoyable for the participants?

According to the correlation between the interactivity level of the content and the participatory effects of storytelling [19], the five levels of interactivity can be defined as follows:

Level 1: "Peripheral Interactivity" (Digital literature poetry)

Level 2: "Interactivity Affecting Narrative" (Hypertext fiction form)

Level 3: "Interactivity creating Variations in a Defined Story" (Visual novel form) 
Level 4: "Real-Time Story Generation" (SIMS-like form where changes are seen in real-time) Level 5: "Meta-Interactivity" (Tool making capability to change the output structure)

The first level of interactivity is what one experiences in the elevator, as described above. It is peripheral interactivity where the audience selects a story as if pressing a floor button and views that part (passive, near-observer attitude). The second level of interactivity is a much more familiar one. It affects narration, as the elements of making a story are predetermined but the story's phases or patterns appear to the viewer differently depending on the interactive mechanism. A good example of this level is a well-structured Internet site with a set of databases behind it. Touring a science museum also gives this level of experience, as in the Internet homepage where the viewer can choose to enter different rooms with different themes. This is a method suitable for hypertext fiction. The readers see many links that are connected to each part of the text, like a website, and choose the link they want in order to progress through the stories, so the readers see different stories depending on the path they have chosen, but cannot influence the story they see.

The third level of interactivity is problem-solving-oriented storytelling in games. A quest narration can evolve into various branch stories and also suggest different endings. The players receive and perform missions, and they experience different stories depending on the success or failure of the mission. In this process, the designer even prepares endings, such as a game-over message if the players go in the wrong direction or fail in the mission, in order to guide the players in the direction that the designer has planned. Then, the players start the game again and eventually succeed in the mission to complete the story. As in Figure 1, this would look like a tree with large and small branches originating from the main stem, the structure of which is seen in the games of multi-endings, such as Princess Maker. The main distinction between Level 3 and Level 2 is that Level 3 has no predetermined ending or structure. By solving problems, the user can decide to add a new branch and a story to it. Thus, the final outcome of the game cannot be predicted. In this regard, Level 3 is dynamic while Level 2 is static, so we designed and tested Level 3 game content in this research.

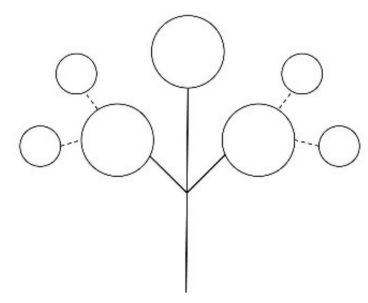

Figure 1. Tree-Branch Structure.

The fourth level of interactivity has a generative algorithm that enables selecting an action and facing the turn of accidental events. To deal with such unforeseeable occurrences, the player has to devise and choose another set of actions, as in SIMS.

The fifth type of interactivity is the most advanced level, where one can design a novel stage in a computer game, craft new clothing for an avatar, connect a real object with a new move, and possibly expand the experiential zone of the previous story world. At this level, players (i.e., the user and the audience) become coauthors in narrating the story, as in alternate reality games (ARG).

Here are a few examples of storytelling in different levels. Olafur Eliasson installs giant blocks of ice across London (Figure 2). In this Icewatch example, the role of the viewers is a quite passive one, as they just watch the ice melting away over time (and perhaps make inferences regarding the polar ice melting due to anthropogenic activities); therefore, it is Level 1 storytelling. 


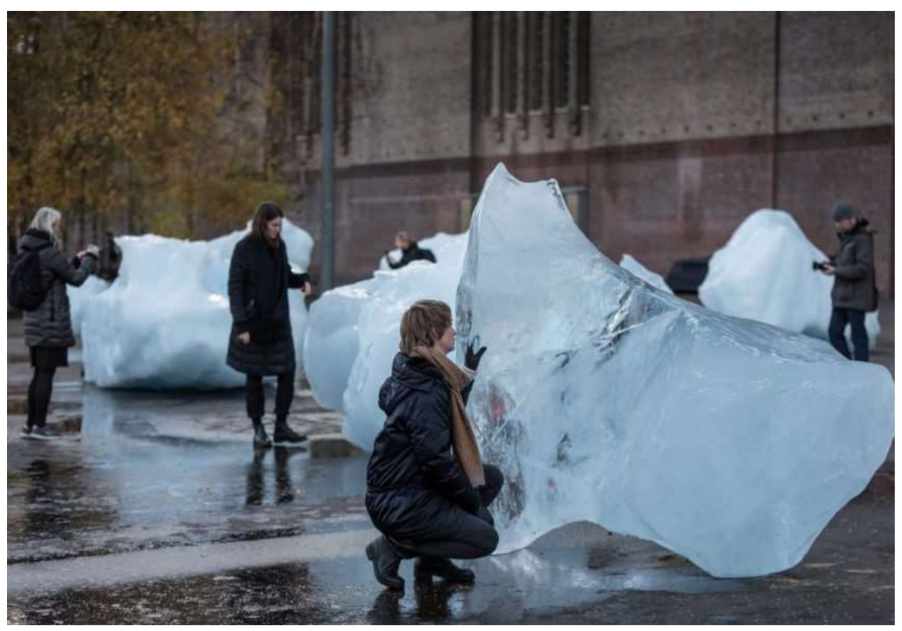

Figure 2. Icewatch, an Example of Level 1 Storytelling (https://www.dezeen.com/ice-watch-olafureliasson-installation).

A more advanced type of participatory storytelling calls for the viewers' involvement. In media art, a public display made up of plastic bags added by the public eventually takes on a shape that is not predetermined, but defined by an accidental turn of events (Figure 3). As the viewers participate in the art creation, the awareness of the importance of reducing the usage of plastic bags is developed in their mind.

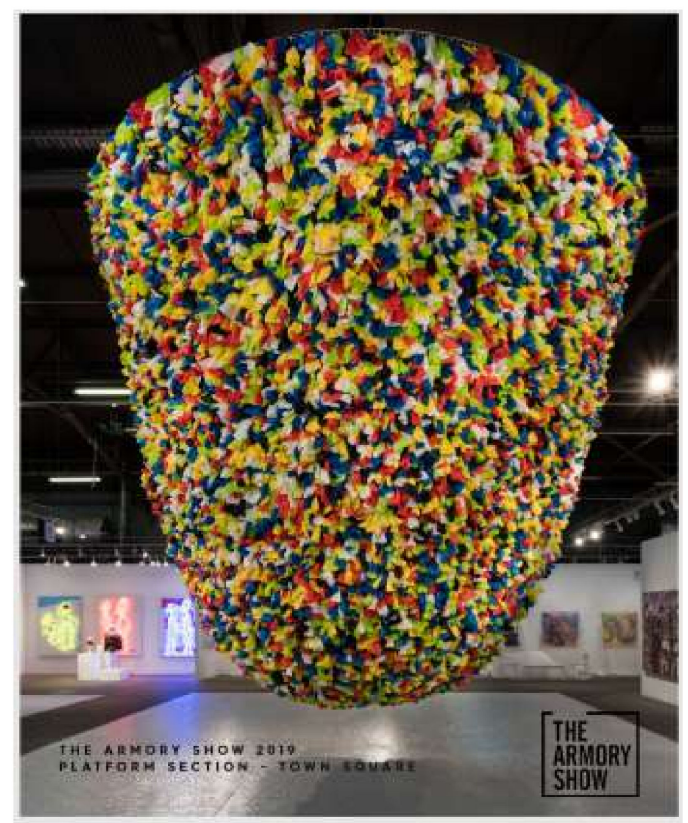

Figure 3. Public Art with Plastic Bags, an Example of Participatory Storytelling.

A social game or crowd funding are excellent examples between Level 4 and Level 5, the most advanced forms of participatory storytelling. Currently, the Dad Dritte Land Art Garden Project asks for the participants' donations and allows them to watch the development of a garden made of plants brought from both South Korea and North Korea (Figure 4, left). If a donation is made, rewards ranging from tote bags (Figure 4, right) to thank-you cards, artwork frames and a musician's performance ticket are given to donors. 

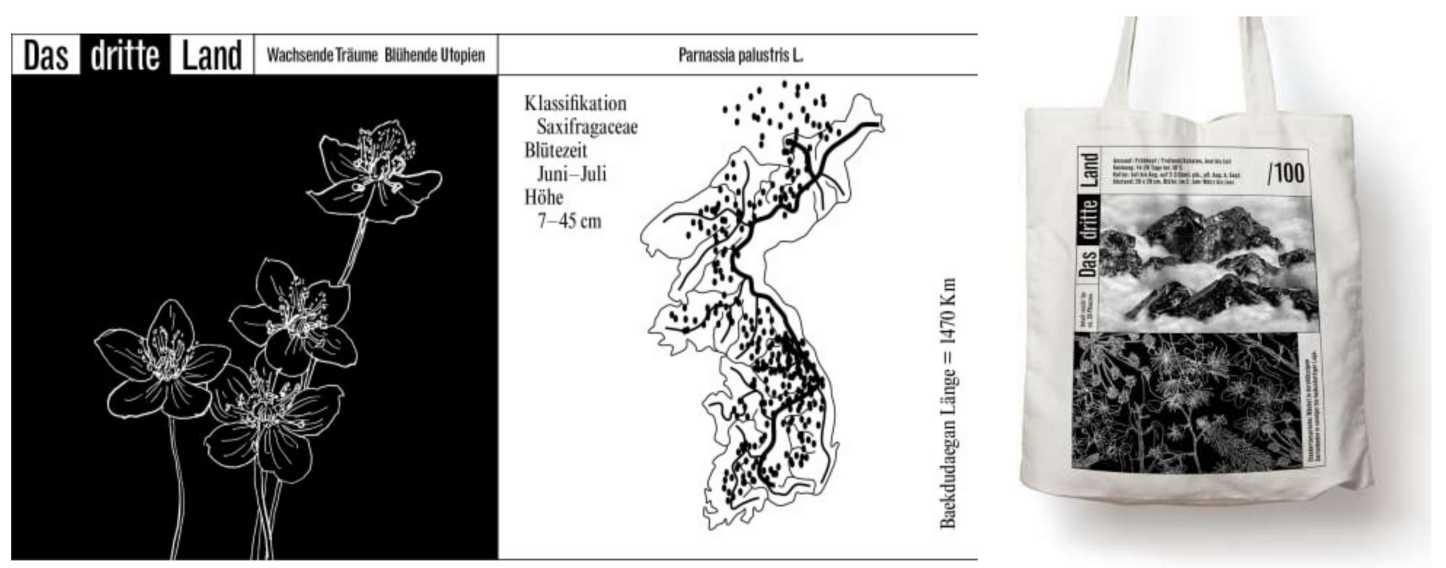

Figure 4. Crowd Funding Project with Rewards, an Example of Advanced Participatory Storytelling https://wemakeit.com/projects/das-dritte-land-art-garden?fbclid=IwAR0oYgpmKW3GXJDPV59A98aPNR9roKKSz9upMcXWIcA8iVT05UNopolheo\&locale=en).

Currently, the gardening project is closer to a Level 4 example with a potential to reach Level 5, depending on how much the artist opens up the designing of the garden to the donors' ideas and actual participation. Below, a Level 5 example is designed around crowd-based, social volunteering and tested in this study.

\subsection{Study Methodology and Focused Group Interview}

As defined above, there are 5 levels of pro-environmental storytelling in game (and art) contents that have a specific environmental theme and a certain objective to change the player's (and viewer's) mindset and to provoke participation. In this study, after summarizing the first (basic) level results in our previous study, we designed higher (intermediate and advanced) levels of pro-environmental storytelling in various forms of games contents. The objective of this study is to test if a more advanced level of storytelling can effectively bring about a change in the viewer's mindset and participation (e.g., the willingness to make donations to an environmental campaign). The test results can lead to practical implications on how to design pro-environmental messages most effectively, by using interactive storytelling for game (and art) contents.

In this research, we summarize Level 1 storytelling that used art, and test Level 3 and Level 5 of interactivity using game contents as follows:

Level 1: Donation to an Environmental Campaign

Level 3: Serious Game for Environmental Awareness

Level 5: Social Game for Environment-related Mission Accomplishment

For the Level 1 Study, we implemented art as a main medium [10]. While previous studies looked mostly at the role of knowledge and socio-technical approaches in environmental innovation (e.g., [21,22]), our study explained how art-based storytelling could induce consumers to take pro-environmental action. We observed how consumers reacted with and without art-based storytelling when they were asked to join a pro-environmental campaign. In this level, there are three main paths in which arts could tell a story in promoting environmental sustainability: communicating information (knowledge), forming empathy toward the natural environment (emotion), and being unified with ecological sustainability [23].

In the Level 3 Study, a serious game is developed. Interactivity is designed such that the player can continue solving quizzes to make progress from stage to stage. At each stage, players are given an assignment to solve a problem before exiting a room (stage) in order to enter the next one. Moreover, the story is not predetermined. As a player is navigating through different rooms, unique stories are unfolded, so that each user can experience quite different outcomes. This feature evokes a 
high level of attention and active participation by the players. The end goal of the game is to prevent future environmental disasters (a doomed earth), so that humankind is saved. Because the participant is more actively involved in the storytelling of the game, the level of interactivity increases; therefore, the end-goal of the game, that is environmental awareness in this case, is introduced in the player's mind. This effect will be analyzed in a focused group interview.

In the Level 5 Study, which is the most advanced level of interactivity, an environmental mission is given to the users. Players are given an assignment to accomplish a mission but no preset ways are enforced. In other words, both the initial participation and the level of involvement as well as planning for the mission are entirely left to each player. As the player navigates through the mission-accomplishing process, he or she gets a unique experience and ends up with his or her own story as to how the journey and self-motivation have unfolded. This feature prompts an even higher level of focus on the game and the voluntary participation of the users.

When studying the results of Levels 3 and 5, this paper intends to use Focused Group Interview (FGI), which is a qualitative research methodology. FGIs are conducted with the participants who have experienced the phenomenon to be studied and are able to express their experiences well, make a list of meaningful statements, describe and record what they experienced with this phenomenon, and structurally explain how the experience happened [24].

This method has the usefulness of allowing direct communication with the participants about research issues and secure specific contents through that communication. FGI has the advantage of being able to obtain more three-dimensional results, in that it can reflect the motives, attitudes, and opinions of participants that cannot be captured by questionnaire-based quantitative research. In addition, FGI has the advantage of being able to collect in-depth and practical opinions through group discussions that are not revealed in quantitative techniques such as surveys. Therefore, this study used FGI as one of the qualitative research methodologies.

Because the main targets of the campaigns that people can participate in are those who have been exposed to general games, media art, and social media, and are in need of promotion of eco-friendly perceptions, students in their 20s, who used many of the contents that are examples of this paper, were recruited, and interviews were conducted with them. As such, in order to examine which type of storytelling at varying levels of interactivity is most effective to convey environmental messages, a focused group interview is conducted to see such effects among game users. The selected interviewees should have some level of environmental awareness/literacy to begin with, and they are to have interest in, and to be capable of playing, the game contents in this research. As described below, the final interviewees turned out to be 9 and 10 participants for Level 3 and Level 5 games, respectively.

\section{Results and Discussion}

\subsection{Summary of Art-Based Storytelling (Level 1)}

Lee (2019) summarizes the experiment conducted among a group of consumers in the U.S. and Korea. The research results showed that people changed their attitude after having seen the art (of green trees and children playing underneath) whether to participate in a tree planting program. This shows the storytelling effects of art that could influence people's emotions and behaviors, but was the least interactive form of storytelling. We examine more effective ways of environmental storytelling at advanced levels in this research below.

\subsection{Level 3 (Creating Variations in a Story) Results}

This level consisted of a serious game that was designed to promote eco-friendly perceptions. One example of this kind of game is the escape room game prepared by Soonchunhyang University, that was based on the open chant function in KakaoTalk. For this study, a KakaoTalk escape room game, $<$ A New Researcher's Diary>, was created to spread eco-friendly perceptions through storytelling, the setting of which was a futuristic virtual dystopia with high levels of air pollution due to fine dust. 
From 3 November to 26 December 2019, a total of 294 subjects participated in this study. Of this group, 80 players successfully reached the game's last stage, no. 30, and 9 of the players that finished the game were recruited to participate in an FGI. Note that 80 participants reached the end in the Level 3 serious game, and 9 out of the 80 were interviewed. So, 80 out of 294 participants managed to reach the ending. This number was considered appropriate and balanced between the level of difficulty and the interest in continuing to play the game, because if people do not play the game completely, the effect of serious gaming may also decrease.

In order to determine what kind of experience the game made for Level 3 gave the participants regarding the promotion of eco-friendly perceptions, a total of 9 participants were randomly selected out of the 80 successful players. The FGI was conducted for about one hour and a half, from 19:00 to 20:30 on 5 December 2019, in the student project room of Startup Plaza at Soonchunhyang University. The contents of the interview were recorded with the consent of the participants, and then they were analyzed. The general characteristics of the study participants are shown in Table 1, below. The questions were divided into three areas: an area to identify the interest in the game, the cognition area (to check whether the participants recognized in the process of the game that it was aimed at promoting eco-friendly perception), and the usefulness area (to check whether the participants actually raised their eco-friendly perceptions after the recognition).

Table 1. Description of Level 3 Game Participants Interviewed.

\begin{tabular}{cccc}
\hline Gender & Age & $\begin{array}{c}\text { Whether the Participants Majored in Subjects } \\
\text { Related to Game and Media Art }\end{array}$ & Level of Education \\
\hline 6 female/3 male & $20-30$ & 4 majors/5 non-majors & 9 undergraduate students \\
\hline
\end{tabular}

This type of game was devised under the following considerations. $<$ A New Researcher's Diary $>$ is a game that has 30 stages in which a player can "escape" KakaoTalk's open chat rooms by solving puzzles (Figure 5). Rather than escaping from a physical space, players enter an open chat room and are provided a link to a cover image, which contains a hidden password that they must unlock. Then, the players can escape the current room through another link to the next room, which is displayed in the chat room. Players move in this manner from room to room by unlocking the passwords from the cover images provided in each chat room; therefore, the players must pay attention to the information in each cover image, each of which promotes eco-friendly perceptions that were intended by the developer.

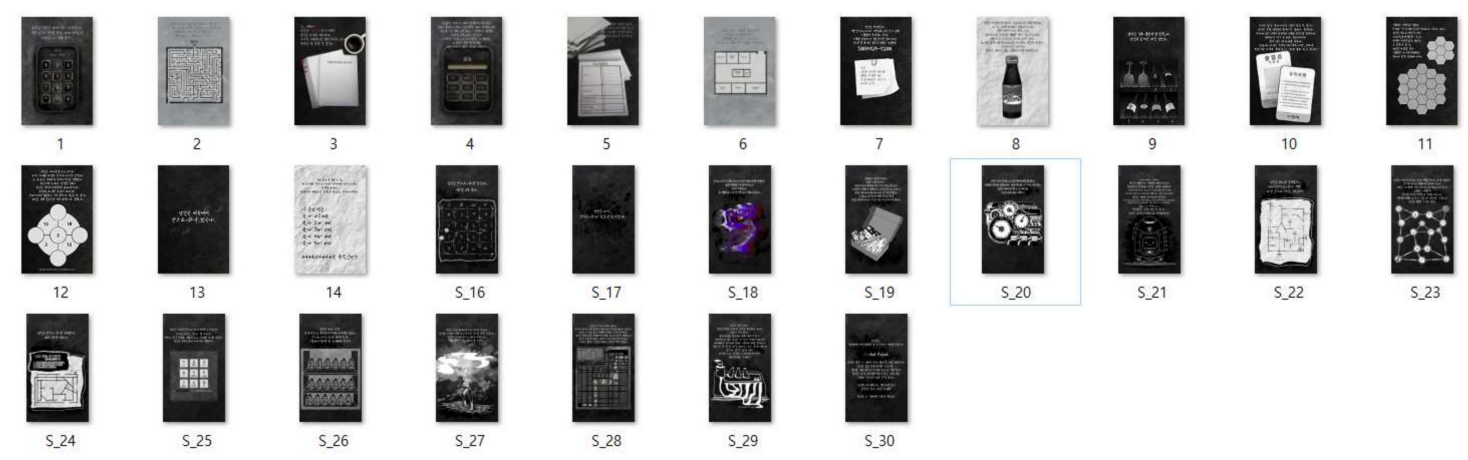

Figure 5. Thirty Stages Design of $<\mathrm{A}$ New Researcher's Diary $>$.

This game describes its worldview in the first room (Figure 6), <A New Researcher's Diary $>$, which is a prologue that players must read to enter the game. The narration explains: "In 2029, people who inhaled dense smog began to die, and this was attributed to fine dust." In the game, the player is one of the researchers who are working to eliminate this smog, and, as the game begins, 
they join a research institute. The password that allows a player to enter this room is "2029," that is, the year when fine dust emerged as smog.
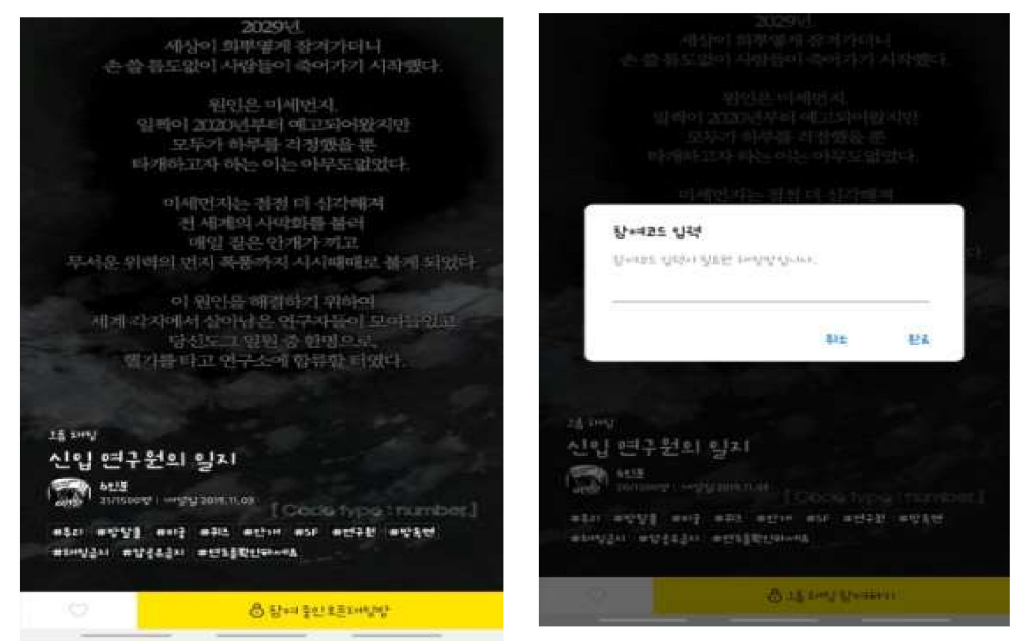

Figure 6. The First Stage of $<$ A New Researcher's Diary $>$.

To solve this puzzle and enter the room, the player must inevitably read through the cover image, including the corresponding worldview description. This mechanism continuously engages the player in the experience of searching the cover image for a hint in order to move or "escape" to the next room. The cover image continues to evolve, beginning with an image of a researcher being replaced by the player, which is followed by an image of the player as the only survivor in a crashed helicopter, and an image of them falling into a stormy desert. In other words, the act of the player escaping the KakaoTalk's open chat room is perceived as a corresponding action along the storyline as the player survives the smoggy world.

The game creates the feeling that the player's survival is threatened due to the fine dust, which persists as the story progresses. This feeling is created through the setting of the game, which requires the use of unique tools to survive the world full of fine dust, such as an escape capsule and gas masks, and the opening warning that "This space is not safe". However, the results showed that there was a gap between the in-game objective to "escape" each room and finish the game and the internal purpose to "heighten eco-friendly perception" of the players. The FGI subjects replied that they became indifferent to the dystopian worldview due to the fine dust as they approached the end of the game. In their responses to another question in the interview, the subjects answered that, as the narrative progressed, it focused more on the emotions between the main character and the robot and less on the fine dust, and thus the subjects became engrossed in clearing the puzzles, neglecting the worldview and storyline.

These two responses have the same context. First, even with a serious game, the goal to play the game itself is prioritized over the purpose of promoting eco-friendly perceptions. Players tended to focus more on the declared mission to "solve the puzzle in the cover image to move to the next room". Second, even if the purpose of promoting eco-friendly perceptions is achieved, the achievement was limited to recognition because the purpose of this game lacked a specific code of conduct for reducing the fine dust.

Among the players who participated in this game, those who had not been interested in environmental problems such as fine dust adhered to their previous belief that it was meaningless to raise awareness on an individual level even after completing the game. Specifically, the players believed that because macroscopic problems such as fine dust are attributed to causes occurring at the corporate or national level, it is meaningless to raise awareness at the individual level. The players thought that the environmental threats that are appearing in the real world can be solved through the microscopic movements of society as a whole rather than by triggering the actions of individuals, 
which this game intends. However, the players mentioned that the active provocation of reactions would be more influential. What was interesting was that, during the interview, the participants talked about their experiences in playing this kind of game and pointed out the limitations of the game.

Level 3 games are focused mainly on raising awareness of problematic situations. For example, Aqua Republica (2019), which is a serious game developed by the United Nations Environment Programme (UNEP) for environmental education for the youth, is a strategic simulation game about sustainable water use. Furthermore, EcoFriendz, developed by Hangame, is a strategic simulation game about reducing $\mathrm{CO}_{2}$ emissions. While these games are effective in raising awareness of problematic situations at the global level, it may be unclear what each player can do in response to this macroscopic problem. The eco-friendly way of thinking promoted through games is fleeting and does not induce specific actions.

Level 4 games increase the connection with reality because these games operate in real time. For example, My Tree, produced by Beimsupictures, virtually connects a user to a physical tree in the Seoul Forest when the user grows a tree in the game. As a result, the time and devotion a user spends in the process of growing a tree in My Tree is utilized to grow a physical tree. Nevertheless, if a game progresses in real time without any induction of specific actions, eco-friendly perceptions will also be dispersed due to the prioritized purpose of the game. In order to turn specific actions into everyday actions, further experiments are necessary in which players are allowed to create the rules of the game by themselves.

\subsection{Level 5 "Meta-Interactivity" (With Capability to Change the Outcome of a Story) Results}

How does Level 5 interactivity promote eco-friendly perceptions? This study provides two examples of such games, where users actively and spontaneously created game rules in mutual cooperation. The first example is the \#Trashtag Challenge, that requires users to share photos on social media before and after removing garbage that had accumulated in public places or natural landscapes (Figure 7). This promotion, which started after the Ice Bucket Challenge, requires users to undergo three stages. First, a user searches for a place, such as a beach, park, road, hill, or event venue, that requires clean-up. Second, the user takes pictures of the site before removing the garbage. Subsequently, the user cleans up the garbage that harms the natural environment, such as plastic bags and discarded materials, and then the user takes selfies with the bag of garbage that was collected and posts the photos to an SNS with the hashtag \#Trashtag. This promotion not only started from the voluntary participation of SNS users but also developed through the induction of a simple and specific action to remove garbage, thus leaving a deep impression on users.
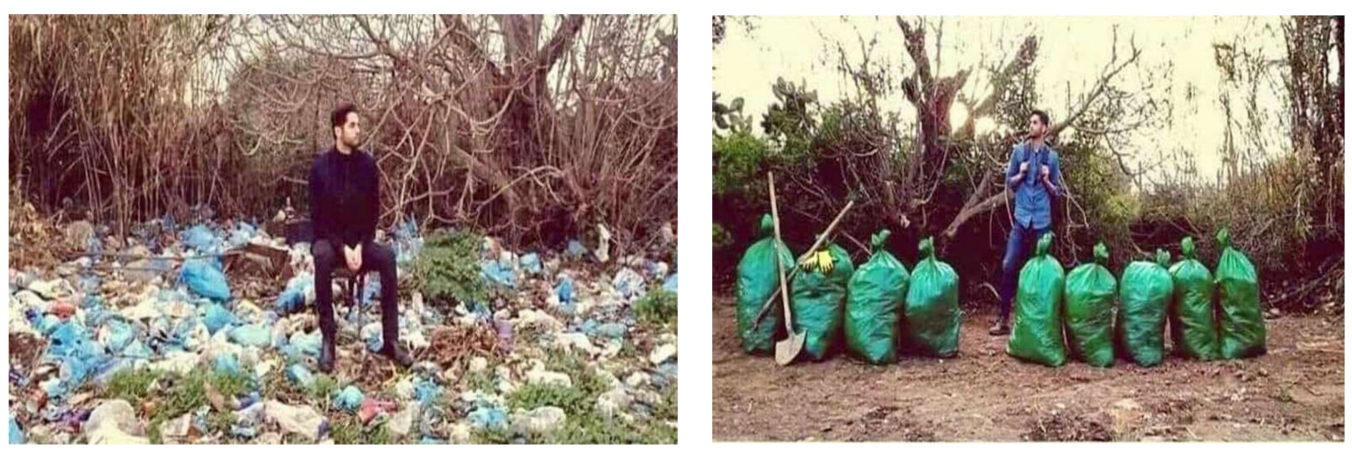

Figure 7. Trashtag Challenge.

A second example of voluntarily competing and playing using media is the $<$ Forest: Stay Focused $>$ application (Figure 8). It basically helps users increase their concentration and build an efficient lifestyle away from their smartphones. The user first sets his or her concentration time, selecting from the available options of at least "10 to $120 \mathrm{~min}$." The user selects a tree provided by the Forest with the intention to grow the tree as part of his or her own forest or garden composed of healthy trees. 
The tree grows if the user keeps the app open for the duration of the concentration time, which prevents them from using their phone for other purposes and encourages them to focus. The user also earns virtual coins in the game as a reward for growing a tree and can plant physical trees on Earth using virtual coins through a partnership with the nonprofit organization Trees for the Future. In the app, users voluntarily compete in groups to plant more trees without the intervention of any planner. The interactivity in the game corresponds to Level 5 in that players compete with friends to see who can stay concentrated the longest.
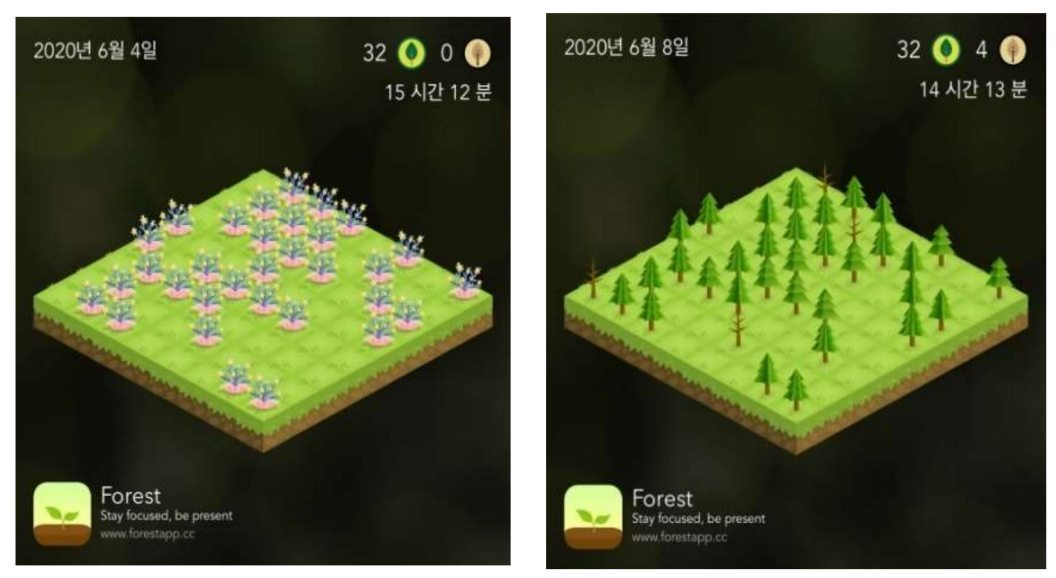

Figure 8. Screen displays of $<$ Forest: Stay Focused $>$ application playing.

Our research team at Soonchunhyang University conducted an FGI with 10 students who utilized the $<$ Forest: Stay Focused $>$ application. In order to find out what kind of experience the participants had with the Level 5 application, this study selected the participants for this FGI. To this end, among students who have voluntarily used this application for at least two weeks, 10 students, who can be considered voluntary participants, because their concentration time in this application was at least $120 \mathrm{~min}$, were randomly selected. The general characteristics of the research participants are shown in Table 2, below.

Table 2. Description of Level 5 Game Participants Interviewed.

\begin{tabular}{cccc}
\hline Gender & Age & $\begin{array}{c}\text { Whether the Participants Majored in Subjects } \\
\text { Related to Game and Media Art }\end{array}$ & Level of Education \\
\hline 6 female/4 male & $20-30$ & 4 majors/6 non-majors & 10 undergraduate students \\
\hline
\end{tabular}

The 10 interviewees were students in their 20s from various majors who had voluntarily competed in the app in various methods. The interviewees' in-game achievements ranged from growing four trees (120 min of concentration) to148 trees (3900 min), as shown in Table 3. Because of the COVID-19 situation, the FGI was conducted through a live video conference for two and a half hours, from 16:00 to 18:30, on 4 June 2020, and the contents of the FGI were analyzed after cloud recording. The contents of the interview were divided into five areas.

Five questions were asked in the interview to investigate: (1) whether the players voluntarily increased the time they spent focusing to play the game; (2) whether the players recognized changes in their environmental perception and behavior, such as planting trees or protecting the forest, by using this app; (3) whether the players had ever had an eco-friendly perception before playing this application; (4) whether the players had ever engaged in environmental perception and behaviors, such as planting trees or protecting the forest, before playing this application; and (5) whether the players developed eco-friendly perceptions after playing this app, and whether these perceptions have led to environmental perception and behaviors, such as planting trees or protecting the forest. 
Table 3. Concentration time in Forest application and the no. of trees grown (10 students, June 2020).

\begin{tabular}{ccc}
\hline Student & Focus Time (min) & Trees Planted \\
\hline 1 & 3900 & 148 \\
\hline 2 & 1960 & 43 \\
\hline 3 & 1727 & 69 \\
\hline 4 & 1265 & 42 \\
\hline 5 & 1260 & 42 \\
\hline 6 & 960 & 37 \\
\hline 7 & 228 & 10 \\
\hline 8 & 220 & 10 \\
\hline 9 & 190 & 9 \\
\hline 10 & 120 & 4 \\
\hline
\end{tabular}

The interviewees, in response to Question (1), said that the longer they spent without using their cell phone, the more motivated they became to view the trees that they had planted in the process of voluntarily increasing their concentration time. Some interviewees said that when they picked up their cell phone from time to time, they placed it down after viewing the screen that showed that a tree was being planted. This answer reveals that eco-friendly perception naturally occurred during the users' voluntary competition.

The interviewees' response to Question (2) revealed that the players also recognized environmental protection and tree planting during the voluntary competition. The application allows a user to plant a physical tree by collecting 2500 won in coins, which took about one to two weeks. When the user was able to plant a physical tree with the collected 2500 won, their affection for the tree grew.

Five out of the 10 students who were interviewed said they tried to collect coins after realizing that they could plant physical trees by stacking coins. Many students understood the message that the environment can be protected by reducing the use of their cell phones. Among the interviewees, there was one student who felt more responsible for protecting a tree from being exposed to damage if he gave up.

Questions (3) and (4) asked the participants to compare their attitude and behavior before and after using this app. Many students answered that they had a vague concept of the need for environmental protection but never put it into practice. Students answered that they had previously cared about energy saving, had experience planting trees in other countries through a game called Tree Planet as a teenager, and added that, after playing $<$ Forest: Stay Focused $>$, they were searching more specifically for eco-friendly campaigns. The students who remembered participating in a tree planting event during middle and high school also said that they usually care about saving energy and are searching for more specific environmental actions after playing this app.

The students who had experienced eco-friendly campaigns or played Level 3 games that promote eco-friendly perception reported that they already had an eco-friendly perception. However, the results confirmed that even students who had not directly participated in previous eco-friendly campaigns already had a vague perception of environmental protection before using the $<$ Forest: Stay Focused $>$ app.

In response to Question (5), which concerned whether these perceptions have led the interviewees to increased environmental perception and behaviors, such as planting trees or protecting the forest, all 10 interviewees answered yes. Some students answered that they would search for opportunities to participate in a wider variety of eco-friendly campaigns after using this app, and some hoped that the social tree planting challenge would become more diverse.

These results show that the Level 5 campaign not only promoted eco-friendly perceptions but also helped induce specific actions in everyday activities as well as continuous actions. This campaign 
has been deeply perceived by users in that it encouraged users to complete simple and specific actions that concentrate on daily activities related to using a smartphone.

In the results of the interview with students, it is necessary to pay attention to the students who had already played games corresponding to Levels 3 or 4 and those who had already recognized eco-friendly perceptions. All 10 interviewees had some degree of eco-friendly perception. Although 2 students had played Level 3 games, other students had already been exposed to Level 1 campaigns, and, thus, all the students had a vague perception of the need to protect the environment and save energy. However, when they were asked if they had actually taken actions, they answered that they were just in the idea stage.

The students who engaged in specific actions-i.e., to place down their cell phones-through the Level 5 activity found that this action helped protect the environment. In addition to the discovery, these students took a specific action. The students also answered that they would use the cell phone in this manner in the future and would try other environmental campaigns if such exist.

Many people already have eco-friendly perceptions because they have been exposed to eco-friendly campaigns through various media. Thus, it is necessary to apply interactive storytelling to such campaigns, which will induce users to participate in a specific action in real time and move the level of interactivity a step further from simply promoting eco-friendly perceptions. It is highly likely that users who have participated in such campaigns will maintain eco-friendly perceptions in a more sustainable manner.

\section{Implications for Practicing Environmental Storytelling}

The results of Levels 1,3, and 5 experiments confirm the propositions of this study. Storytelling approaches do have a positive effect on the user's mind toward environmental protection, and more advanced, game-based storytelling had an even larger impact on people's willingness to take actions for the environment. Given this outcome, the authors suggest three modes of effective environmental storytelling strategies, as presented in Table 4.

We can classify three different target groups of environmental storytelling, as shown in Table 4.

1. Target Group 1: People not yet having eco-friendly perceptions and little awareness of environmental problems.

2. Target Group 3: People with some knowledge of environmental issues and a general interest in environmental protection, but who have not taken part in environmental campaigns and who like to play games with a social mission.

3. Target Group 5: People with prior knowledge of environmental issues, showing a high level of interest (even concern) and voluntarily participating in actions to resolve them.

Level 1 storytelling is not necessarily the least effective mode when it comes to the arts. What this research suggests is that a storytelling approach can be coupled with artwork such that it can have more interactive features. This advanced storytelling feature used in arts will establish a stronger interaction with the audience/viewers (i.e., participation in a piece of artwork or some problem to be solved, like puzzle-making), so that they are effectively engaged in the dialogues that the artist wishes to have regarding social issues. 
Table 4. Interactive Storytelling Modes and Their Usages with Art/Game Contents.

\begin{tabular}{|c|c|c|c|c|c|}
\hline & Medium & $\begin{array}{c}\text { Degree of } \\
\text { Interaction }\end{array}$ & Effect & Description & Target Group \\
\hline $\begin{array}{l}\text { Appreciative } \\
\text { Mode: Level } 1 \\
\text { Storytelling }\end{array}$ & $\begin{array}{l}\text { Arts and } \\
\text { Visual } \\
\text { Elements }\end{array}$ & $\begin{array}{l}\text { Viewing or } \\
\text { Listening }\end{array}$ & $\begin{array}{l}\text { Emotional } \\
\text { Change and } \\
\text { Compassion }\end{array}$ & $\begin{array}{l}\text { Use of diverse arts } \\
\text { that exhibit audio } \\
\text { visual elements to } \\
\text { invoke people's } \\
\text { emotional } \\
\text { responses to } \\
\text { environmental } \\
\text { conservation }\end{array}$ & $\begin{array}{c}\text { People not yet } \\
\text { having eco-friendly } \\
\text { perceptions and } \\
\text { little } \\
\text { environmental } \\
\text { problems } \\
\text { awareness }\end{array}$ \\
\hline $\begin{array}{c}\text { Engaged } \\
\text { Mode: Level } 3 \\
\text { Storytelling }\end{array}$ & $\begin{array}{l}\text { Gamified } \\
\text { Content }\end{array}$ & $\begin{array}{l}\text { Participatory } \\
\text { Game Playing } \\
\text { or Problem } \\
\text { Solving }\end{array}$ & $\begin{array}{l}\text { Awareness } \\
\text { Increase on } \\
\text { the Issue }\end{array}$ & $\begin{array}{l}\text { Participation in } \\
\text { social issue games } \\
\text { to solve problems } \\
\text { or produce benefits } \\
\text { related to the } \\
\text { environment }\end{array}$ & $\begin{array}{l}\text { People with some } \\
\text { knowledge of } \\
\text { environmental } \\
\text { issues and general } \\
\text { interest in } \\
\text { environmental } \\
\text { protection }\end{array}$ \\
\hline $\begin{array}{c}\text { Actioning } \\
\text { Mode: Level } 5 \\
\text { Storytelling }\end{array}$ & $\begin{array}{l}\text { Game-based } \\
\text { Events }\end{array}$ & $\begin{array}{l}\text { Voluntary } \\
\text { Campaigns or } \\
\text { Challenge } \\
\text { Competitions }\end{array}$ & $\begin{array}{c}\text { Action } \\
\text { Readiness } \\
\text { regarding the } \\
\text { Issue }\end{array}$ & $\begin{array}{l}\text { Mission-given } \\
\text { challenges among } \\
\text { the entrants of the } \\
\text { event who create } \\
\text { actionable } \\
\text { solutions to the } \\
\text { social issue }\end{array}$ & $\begin{array}{l}\text { People with prior } \\
\text { knowledge of } \\
\text { environmental } \\
\text { issues, showing } \\
\text { high level of } \\
\text { interest }\end{array}$ \\
\hline
\end{tabular}

It is also important to progress from Level 3 storytelling to Level 5 storytelling in serious games, because changes in actions matter, and not just emotional feelings or a higher awareness of social issues. Users who engage in Levels 3 to 5 actually try to solve a problem by participating in interactive media. In the process, it is highly likely that the users will accept the already designed eco-friendly perception as their own. However, in the case of Level 3, in the process of gamification, the purpose of the game could be prioritized over the goal of promoting eco-friendly perceptions. Level 5 urges users to voluntarily participate in specific actions in real time. This level is important in that the users, who have already been exposed to various campaigns to promote eco-friendly perception but may have only had a vague conception of environmental protection without the induction of specific actions, are highly likely to maintain this perception. In order to achieve meaningful environmental innovation and sustainable development, not only industrial technologies and government policies but also the consumer's awareness change and tangible actions should follow. In this regard, the results in this research help increase environmental awareness and motivation for customer actions aimed at preserving the environment.

\section{Conclusions and Future Research}

This research analyzed the role of storytelling in environmental innovation, and consisted of a series of studies to examine how environment-themed arts, gamified contents, and well-constructed environmental challenge games influence people's awareness and attitude toward environmental conservation activities. The results showed that the different modes of environmental storytelling impact people's perception and actions regarding the protection of the environment and their willingness to be involved in environmental campaigns. This research contributes to the field of environmental storytelling by defining varying levels of storytelling and concrete story development strategies using game contents. The case studies demonstrate through actual experiments how games are employed in effective storytelling modes to raise users' awareness and emotional buy-in for possible actions.

Various cases of environmental storytelling in the three modes developed in this article should be further examined for their effectiveness on pro-environmental consumption. The theoretical and 
experimental results in this research can be improved by incorporating more gamification literature and innovation studies. That is, an integrated analysis of gamification and innovation studies should be conducted. In addition, it would be useful to apply our findings to more participants from diverse regions and backgrounds.

Games can be an effective platform for change management in environmental innovation. Not just technological development but also usage and operational changes can be expected if users are properly educated and motivated via game-oriented storytelling. In this regard, this research has introduced a new approach framework on game content-based storytelling for social issues in practical detail.

Author Contributions: Both authors conducted original research and wrote this article. All authors have read and agreed to the published version of the manuscript.

Funding: This research was funded by Soonchunhyang University Research Grant No. 20180997.

Acknowledgments: The authors acknowledge the students' participation in experiments and interviews.

Conflicts of Interest: The authors declare no conflict of interest.

\section{References}

1. Murray, P.N. How Emotions Influence What We Buy. Psychology Today, 26 February 2013. Available online: https://www.psychologytoday.com/blog/inside-the-consumer-mind/201302/how-emotionsinfluence-what-we-buy(accessed on 5 August 2020).

2. Boronat-Navarro, M.; Pérez-Aranda, J.A. Analyzing willingness to pay more to stay in a sustainable hotel. Sustainability 2020, 12, 3730. [CrossRef]

3. Kim, Y.; Yun, S.; Lee, J. Can companies induce sustainable consumption? The impact of knowledge and social embeddedness on airline sustainability programs in the US. Sustainability 2014, 6, 3338-3356. [CrossRef]

4. Pfanner, E. Big Consumer Products Maker Proclaims the "Green” Virtues of Using Dishwashers. New York Times, 3 September 2007.

5. Kong, H.K.; Lee, J. Do arts influence consumer's emotion for environmental innovation? In Proceedings of the ISPIM Innovation Forum, Boston, MA, USA, 13-16 March 2016.

6. National Geographic. Great Pacific Garbage Patch. National Geographic Resource Library, 5 July 2019. Available online: https://www.nationalgeographic.org/encyclopedia/great-pacific-garbage-patch/ (accessed on 3 August 2020).

7. Hadzigeorgiou, Y.; Judson, G. Toward effective storytelling for raising environmental awareness in young students. J. Adv. Educ. Res. 2017, 2. [CrossRef]

8. Tanner, C.; Kast, S.W. Promoting sustainable consumption: Determinants of green purchases by Swiss consumers. Psychol. Market. 2003, 20, 883-902. [CrossRef]

9. Moezzia, M.; Jandab, K.B.; Rotmannc, S. Using stories, narratives, and storytelling in energy and climate change research. Energy Res. Soc. Sci. 2017, 31, 1-10. [CrossRef]

10. Lee, J. Impacting emotions for pro-environmental consumption: Literature analysis and empirical evidence. Bus. Manag. Res. 2019, 8, 1-7. [CrossRef]

11. Jackson, T. Motivating sustainable consumption: A review of evidence on consumer behaviour and behavioural change. Sustain. Dev. Res. Netw. Cent. Environ. Strateg. 2005, 29, 30.

12. Kagan, S.; Kirchberg, V. (Eds.) Sustainability: A New Frontier for the Arts and Cultures; Verlag für Akademische Schriften: Frankfurt, Germany, 2008.

13. Coleman, L.J.; Bahnan, N.; Kelkar, M.; Curry, N. Walking the walk: How the theory of reasoned action explains adult and student intentions to go green. J. Appl. Bus. Res. 2011, 27, 107-116. [CrossRef]

14. McGonigal, J. Superbetter: The Power of Living Gamefully; Penguin Books: New York, NY, USA, 2015; pp. 106-113.

15. Hildmann, H.; Hirsch, B. Raising Awareness for Environmental Issues through Mobile Device-Based Serious Games, 4th ed.; Microsoft Academic Days: Berlin, Germany, 2008.

16. Arslana, H.O.; Moseleyb, C.; Cigdemogluc, C. Taking attention on environmental issues by an attractive educational game: Enviropoly. Procedia Soc. Behav. Sci. 2011, 28, 801-806. [CrossRef] 
17. McGonigal, J. Reality Is Broken: Why Games Make Us Better and How They Can Change the World; Penguin Books: New York, NY, USA, 2011; pp. 78-88.

18. George, D.R.; Stuckey, H.L.; Dillon, C.F.; Whitehead, M.M. Impact of Participation in TimeSlips a Creative Group-Based Storytelling Program on Medical Student Attitudes Toward Persons with Dementia: A Qualitative Study. Gerontologist 2011, 51, 699-703. [CrossRef] [PubMed]

19. Ryan, M.-L. The interactive onion: Layers of user participation in digital narrative texts. In New Narratives: Stories and Storytelling in the Digital Age; Page, R.E., Thomas, R., Eds.; University of Nebraska Press: Lincoln, NE, USA, 2011; pp. 35-62.

20. Ridder, H.-G. The theory contribution of case study research designs. Bus. Res. 2017, 10, 281-305. [CrossRef]

21. Lee, J.J.; Gemba, K.; Kodama, F. Analyzing the innovation process for environmental performance improvement. Technol. Forecast. Soc. Chang. 2006, 73, 290-301. [CrossRef]

22. Yun, S.; Lee, J. Advancing social acceptance towards renewable energy systems adoption with a socio-technical perspective. Technol. Forecast. Soc. Chang. 2015, 95, 170-181. [CrossRef]

23. Curtis, D.J.; Reid, N.; Reeve, I. Towards ecological sustainability: Observations on the role of the arts. Sapiens 2014, 7, 1-15. Available online: https://journals.openedition.org/sapiens/1655 (accessed on 10 July 2020).

24. Creswell, J.W. Qualitative Inquiry \& Research Design—Choosing among Five Approaches, 2nd ed.; Sage Publications: Thousand Oaks, CA, USA, 2007; pp. 229-230.

(C) 2020 by the authors. Licensee MDPI, Basel, Switzerland. This article is an open access article distributed under the terms and conditions of the Creative Commons Attribution (CC BY) license (http://creativecommons.org/licenses/by/4.0/). 